\title{
Chitosan Application in Textile Processing
}

\section{Lixia Huang, Lin Xiao* and Guang Yang*}

Department of Biomedical Engineering, College of Life Science and Technology, Huazhong University of Science and Technology, China

Submission: August 04, 2018; Published: August 23, 2018

*Corresponding author: Lin Xiao, Department of Biomedical Engineering, College of Life Science and Technology, Huazhong University of Science and Technology, China, Tel: +86 15997480752; Fax: +86 27-87792265; Email: xiaol@hust.edu.cn

Guang Yang, Department of Biomedical Engineering, College of Life Science and Technology, Huazhong University of Science and Technology, China, Tel: +86 27-87793523; Fax: +86 27-87792265; Email: yang_sunny@yahoo.com

Keywords: Chitosan; Textile processing; Antibacterial finishing; Anti-wrinkle finishing; Dyeing; Antistatic finishing

\section{Introduction}

Traditional textile products from fibres such as wool, cotton, silk, polyester, etc. are unable to meet the increasing demand for aesthetics, comfort, healthcare and industrial applications. Functional fabrics possessing antibacterial, anti-wrinkle, dyeing, antistatic and other special properties have received broad attention in the textile industry and fashion world. Chitosan is a product obtained by deacetylation of chitin, which is widely distributed in nature (e.g. shellfish, insects and certain fungi). It has multiple applications in the biomedical and other areas due to its characteristics of excellent biocompatibility, biodegradability, ecological safety, non-toxicity and its versatile biological effects such as antibacterial, antifungal, antitumor activity and low immunogenicity [1,2]. Chitosan has been utilized as an eco-friendly finishing agent to develop functional fabrics in the textile industry $[3,4]$. This article will present brief of chitosan applications in antibacterial, anti-wrinkle, dyeing and antistatic finishing of textiles (Figure 1).

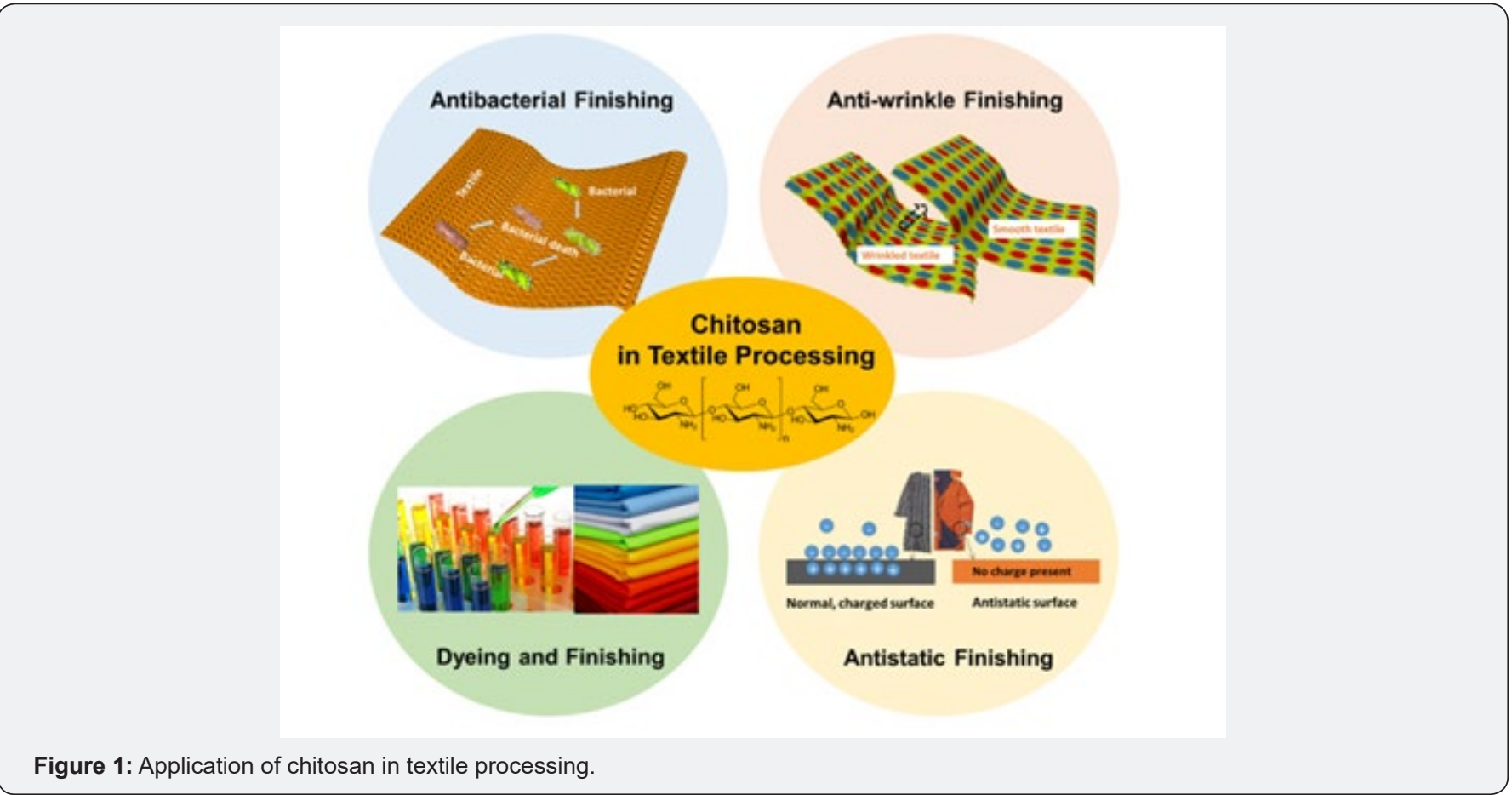




\section{Chitosan in antibacterial finishing of textiles}

Textiles provide nutrients and space for attached microorganisms, which can cause disease transmission and threaten human health. To avoid this, antibacterial treatment of textiles is of great importance. Chitosan has broad-spectrum antibacterial activity, including on Staphylococcus aureus, Escherichia coli and Bacillus subtilis [5]. There are mainly two approaches to manufacture antibacterial fabrics by using chitosan. The first approach is finishing the fabric by attaching chitosan. Aloson et al. [6] used citric acid as a cross-linking agent and sodium dihydrogen phosphate as a catalyst to graft chitosan onto cotton textiles under UV irradiation, which gave them effective antibacterial properties [6]. The second approach is to prepare antibacterial fibers, then weave these antibacterial fibers. Japan Fuji Textile Co., Ltd. developed a stable ultrafine chitosan powder with the particle size of ca. $5 \mu \mathrm{m}$, which was subsequently added to a viscose solution for blending. Finally, fibers named chitopoly with high antibacterial properties were obtained [7].

\section{Chitosan in anti-wrinkle finishing of textiles}

Textile products from natural fibers such as silk, cotton and hemp are favored by a wide range of consumers. However, these fabrics have a rather low elasticity, tending to cause wrinkling and irreversible deformation, thus lowering the aesthetics and comfort of the products. The anti-wrinkle performance of the fabric can be improved using fiber modification, changing the fabric structure, fiber blending or finishing. Finishing with chitosan is a convenient and effective way to improve the antiwrinkle performance of the fabric. Generally, a chitosan solution is first prepared by dissolving chitosan in $1 \% \mathrm{w} / \mathrm{v}$ acetic acid. Then, the fabric is finished in the chitosan solution through a common dipping-rolling-baking process. The chitosan solution penetrates into the fabric fiber to form a water-insoluble protective layer on the surface of the fabric after drying, resulting in a stronger and less deformable fabric. Moreover, chitosan macromolecules fill in the fiber micro-pores, where a large number of intermolecular hydrogen bonds are formed between the hydroxyl and amino groups of chitosan and the polar residues of the fiber molecules. This strengthens the amorphous regions of the fibers and decreases their mobility, thereby providing wrinkle resistance to the fabric. In a study on anti-wrinkle finishing of cotton fabric by chitosan, it was found that the higher the content of chitosan used for finishing, the better the wrinkle resistance of the fabric [8].

\section{Chitosan in textile dyeing and finishing}

Chitosan was originally used as a dye deepening agent in the textile industry. Since it is a cationic polymer, chitosan is considered to be an ideal fixing agent for anionic dyes. Salt-free dyeing is possible by using chitosan with the help of some other additives [9]. The level dyeing effect of chitosan may be explained by the fact that the presence of chitosan leads to a uniform film on the surface of the fiber. It improves the surface properties of the fiber and reduces the Coulomb repulsion between the fiber and the anionic dyes, therefore greatly improving the dye uptake rate. The deepening effect is also due to the protonation of the free amino group on the chitosan molecule under acidic conditions. When the fabric is immersed in the chitosan solution, the positive charge of the fiber is increased, thus the repulsion force between the fiber and the anionic dyes is reduced.

\section{Chitosan in antistatic finishing of textiles}

Polyester fabrics cause clothing to cling the skin because they are prone to static electricity. Employees in industrial fields using delicate electronic instruments are required to put on antistatic workwear [10]. Therefore, the antistatic finishing of fabrics is becoming an attractive subject in the textile industry. The presence of $\mathrm{NH}_{3}{ }^{+}$in the molecular structure of chitosan makes the chitosan-finished fibers have an ion-conducting function in water, which can leak the static charges generated by friction quickly. Meanwhile, electrical neutralization is produced when the charge on the chitosan molecule is opposite to the surface charge on the fiber. In addition, the presence of a large number of strong polar groups such as hydroxyl groups and amino groups on the chitosan molecules makes the chitosan molecules highly hygroscopic, forming a continuous water film on the surface of the fiber. This water film, to some extent, can dissolve carbon dioxide in the air and electrolytes in the fibers, thus indirectly increasing the electrical conductivity of the fabric surface and imparting antistatic properties to the polyester fabric [11].

\section{Conclusions}

Due to its structural characteristics, chitosan can be easily blended with conventional textile fibers such as wool, cotton, silk, and polyester with good compatibility and strong interactions. Functional textiles with antibacterial, anti-wrinkle, dyeing, and antistatic properties can be produced by using chitosan as a finishing agent or fiber modifier. The application of chitosan in the textile industry not only improves the performance and adds value to fabrics but also promotes efficient use of natural resource.

\section{References}

1. Santos-Moriano P, Fernandez-Arrojo L, Mengibar M, Belmonte-Reche E, Peñalver P, et al. (2018) Enzymatic production of fully deacetylated chitooligosaccharides and their neuroprotective and anti-inflammatory properties. Biocatal Biotransformation 36(1): 57-67.

2. Kim SK, Abe S, Ishihara K, Adachi M, Ahn BN, et al. (2018) Antioxidant effects of phlorotannins isolated from Ishige okamurae in free radical mediated oxidative systems. In: Healthcare Using Marine Organisms. Springer Boca Raton, FL, USA, pp. 1-6.

3. Moattari M, Kouchesfehani HM, Kaka G, Sadraie SH, Naghdi M, et al. (2018) Chitosan-film associated with mesenchymal stem cells enhanced regeneration of peripheral nerves: A rat sciatic nerve model. J Chem Neuroanat 88: 46-54.

4. Hamedi H, Moradi S, Hudson SM, Tonelli AE (2018) Chitosan Based Hydrogels and Their Applications for Drug Delivery in Wound Dressings: A Review. Carbohydr Polym. 


\section{Current Trends in Fashion Technology \& Textile Engineering}

5. Ding F, Li H, Du Y, Shi X (2018). Recent advances in chitosan-based selfhealing materials. Res Chem Intermed: 4827-4840.

6. Moattari M, Kouchesfehani HM, Kaka G, Sadraie SH, Naghdi M (2018) Evaluation of nerve growth factor (NGF) treated mesenchymal stem cells for recovery in neurotmesis model of peripheral nerve injury. Craniomaxillofac Surg 46(6): 898-904.

7. Lee EJ, Huh BK, Kim SN, Lee JY, Park CG, et al. (2017) Application of materials as medical devices with localized drug delivery capabilities for enhanced wound repair. Prog Mater Sci 89: 392-410.

8. Vidyavathi M, Farhana SKM, Sreedevi A (2018) Design and Evaluation of Lentil Seed Extract Loaded Bio Scaffolds for Wound Healing Activity. Biomed Pharmacol J 11(1): 503-511.
9. Boroff KE, Boroff A (2018) Performance management-making a difference? Case J 14(1): 25-53.

10. Yegappan R, Selvaprithiviraj V, Amirthalingam S, Jayakumar R (2018) Carrageenan based hydrogels for drug delivery, tissue engineering and wound healing. Carbohydr Polym.

11. Mezzana P (2008) Clinical efficacy of a new chitin nanofibrils-based gel in wound healing. Acta Chir Plast 50(3): 81-84.

12. Niekraszewicz A (2005) Chitosan medical dressings. Fibres Text East Eur 13(6): 54

13. Zhang J, Xia W, Liu P, Cheng Q, Tahi T, et al. (2010) Chitosan modification and pharmaceutical/biomedical applications. Mar Drugs 8(7): 19621987

\section{Your next submission with Juniper Publishers will reach you the below assets}

- Quality Editorial service

- Swift Peer Review

- Reprints availability

- E-prints Service

- Manuscript Podcast for convenient understanding

- Global attainment for your research

- Manuscript accessibility in different formats

( Pdf, E-pub, Full Text, Audio)

- Unceasing customer service

Track the below URL for one-step submission

https://juniperpublishers.com/online-submission.php 